\title{
Effects of Cold and Hot Infusions on Antioxidant Activities of Rosehip Tea Bag
}

\author{
Zeynep Akar ${ }^{1, a, *}$ Erza Orhan ${ }^{1, b}$, Seçil Durmuş ${ }^{1, c}$ \\ ${ }^{1}$ Department of Genetics and Bioengineering, Faculty of Engineering and Natural Sciences, Gümüşhane University, 29100 Gümüşhane, Turkey \\ *Corresponding author

A R T I C L E I N F O A B S T R A C T \\ Research Article \\ In this study, the antioxidant activity values of infusions at different temperatures of the \\ commercially sold rosehip tea bag. To determine the effect of different infusion temperatures on \\ antioxidant activity, 7 different temperatures $\left(0,15,30,45,60,75,90^{\circ} \mathrm{C}\right)$ also including cold \\ infusions temperatures were selected. Infusions of the rosehip tea bags were prepared with packaged \\ Received : 24/02/2021 \\ Accepted : 24/03/2021 \\ drinking water for 5 minutes (recommended time in tea bag packaging) at these temperatures. \\ Antioxidant activity values of the infused extracts were determined by antioxidant activity \\ determination methods: TPC (Total Phenolic Compound), CUPRAC (Cu (II) Ion Reducing \\ Antioxidant Capacity), FRAP (Iron (III) Ion Reducing Antioxidant Power) and ABTS •+ $(2.2-$ \\ azinobis- (3-ethylbenzothiazoline-6-sulphonic acid)) radical scavenging assay. According to the \\ results obtained by the antioxidant determination methods, the highest and lowest activity values \\ Keywords: \\ Antioxidant activity \\ Infusion \\ Rosehip tea bag \\ Temperature \\ Colour \\ for TPC, FRAP and ABTS were measured at $90^{\circ} \mathrm{C}$ and $0^{\circ} \mathrm{C}$, respectively, and a positive correlation \\ was found between temperature and antioxidant activity values. Contrary to the activity values \\ determined in these methods, in the CUPRAC method, the highest and the lowest activity value was \\ measured at $45^{\circ} \mathrm{C}$ and $90{ }^{\circ} \mathrm{C}$, respectively. As determined in the CUPRAC method, infusions of \\ rosehip tea at low temperatures may provide an advantage in terms of the solubility of some \\ phenolics that can be denatured at high temperatures. In addition, rosehip tea infusions at lower \\ temperatures will contribute to lower energy costs.
}

\section{Introduction}

The use of tea as a beverage, which is consumed by hundreds of millions of people in the world today, dates back to the time of Emperor Shen Nung until 2700 BC. (Weisburger, 1997). Of course, for tea, the first thing that comes to mind is Camellia sinensis (L.) Kuntze plant which has a high economic value and is cultivated in 52 countries, mainly China and India (Meegahakumbura et al., 2018). The tea obtained from this plant is generally offered for consumption in major three forms as black tea, green tea and oolong tea, among of them black tea is the most consumed due to its unique aroma and taste all over the world from past to present (Łuczaj and Skrzydlewska, 2005; Li et al., 2013). Besides the consumption of tea as a beverage, it has been reported that reduce the risks of diseases such as coronary heart failure and cancer due to antioxidant properties of its flavonoids content (Gardner et al., 2007). However, it has been pointed out that tea has negative effects on human health such as fluid balance, cognitive function, bone health, dental health and iron status, which are often associated with its caffeine ingredient. (Gardner et al., 2007; Garipağaoğlu and
Kuyrukçu, 2009; Khorshid and Sarı, 2013). Unlike the teas produced from Camellia-sinensis, there are numerous herbs and plants that do not contain caffeine and parts of these plants such as leaves, seeds, roots, barks, flowers and fruits are consumed as tea for their therapeutic effects (Ravikumar, 2014; Petkova et al., 2020). Especially the regular consumption of these teas is very important for human health. Their phenolic and flavonoid contents are effective in treatments and of preventions some diseases (colds, infections, diabetes, lowering blood pressure, controlling cholesterol level, diuretic activity, various types of cancer, heart diseases, obesity) (Chandrasekara and Shahidi, 2018; Poswall et al., 2019). Rose hip tea is one of the most consumed herbal teas and has a wide commercial value in Europe and the United States (Choi, 2009). Rosehip tea is obtained from the fruits of the Rosa canina L. plant that have very rich vitamin $\mathrm{C}$ content, also contains carotenoids, tannins, folate, catechin and proanthocyanidins. These compounds are effective in high antioxidant, anticancer and antimutagenic activities of rosehip tea (Tumbas et al., 2002; Choi, 2009). It is more 
advantageous to consume parts of some plants as hot liquid herbal infusions rather than consuming dried plant parts due to water-soluble phytochemicals such as phenols and flavonoids (Poswal, 2019). However, both the solubility and diffusion coefficient of the solute are in direct proportion to the temperature, but above a certain temperature the phenolic compounds denatured. Therefore, to determine the temperature at which phenolic compounds can dissolve without denaturing will contribute to both effective antioxidant activity and energy cost (Spigno et al., 2007). Therefore, the aim of this study is to determine the ideal infusion temperature of a commercially available rosehip tea bag. Although some studies have been conducted on determining the antioxidant activity of rosehip tea infusion, these studies focused only antioxidant activity of hot infusion rosehip tea; for example, at 60, 75, $90^{\circ} \mathrm{C}$ (Y1ldırım et al., 2015), in 70, 80, $90^{\circ} \mathrm{C}$ (İlyasoğlu and Arpa, 2017) and boiling temperature of water (Petkova et al., 2020).

In the present study different from these studies, rosehip tea infusions were carried out at 7 different temperatures $\left(0-15-30-45-60-75-90^{\circ} \mathrm{C}\right)$, including cold infusions temperature for equal times (recommended time in tea bag packaging) and simultaneously the antioxidant activity of each extract was determined using 4 different antioxidant activity determination methods. Determination of the antioxidant activity values of cold infusions of the bag will contribute to the reduction of energy costs for heating. In addition, the color values of the infused tea bags in flasks at different temperatures were determined by Image $\mathbf{J}$ program.

\section{Material and Methods}

\section{Preparation of Extracts}

Rosehip tea bags used in the study was one of the brands, which are sold commercially on the market in Turkey. In order to determine the change in antioxidant activity values depending on the change of infusion temperature, 7 different temperatures (0-15-30-45-60-75$90^{\circ} \mathrm{C}$ ) were selected. $200 \mathrm{~mL}$ (one water glass) packaged drinking water was poured into 7 different glass beakers. So as to reach different temperature values in infusion, for example, the water temperature was reduced to $15^{\circ} \mathrm{C}$ and $0^{\circ} \mathrm{C}$ by adding ice, while $30-45-60-75-90^{\circ} \mathrm{C}$ was reached with the heater. After the water was reached the desired temperatures, rosehip tea bag was put into the glass beakers, all samples were checked with a thermometer for 5 minutes (recommended time in tea bag packaging) for keeping them constant at the desired temperatures. The antioxidant activities of the extracts were determined simultaneously.

\section{Determination of Antioxidant Activity}

\section{Total Phenolic Content (TPC)}

According to developed method by Slinkard and Singleton (1977), the total phenolic content of rosehip tea bag infusions was determined. First, $50 \mu \mathrm{L}$ of sample solution was diluted with $2.5 \mathrm{~mL}$ of distilled water and 250 $\mu \mathrm{l}$ of $0.2 \mathrm{~N}$ Folin-Ciocalteu reagent was added. Then 750 $\mu \mathrm{L}$ of $\mathrm{Na}_{2} \mathrm{CO}_{3}(7.5 \%)$ was added to the mixture and vortexed. The mixtures were kept at room temperature for 2 hours. Finally, absorbance values at $765 \mathrm{~nm}$ were determined in the spectrophotometer device. A standard calibration graph of gallic acid (500-250-125-62.5-31.25 $\mu \mathrm{g} / \mathrm{mL}$ ) prepared at five concentrations was drawn and the amounts of phenolic compounds in the samples were calculated in terms of gallic acid equivalent (GAE $\mu \mathrm{g} / \mathrm{mL}$ ) with using the function of the line obtained from this graph.

\section{Determination of Iron (III) Reduction / Antioxidant Power (FRAP)}

In the FRAP method, the antioxidant standard Trolox was diluted in 6 different concentrations (1000-500-250125-62.5-31.25 $\mu \mathrm{M}$ ). Firstly, $50 \mu \mathrm{L}$ of samples and standard solutions were transferred in triplicate into tubes. In addition, the same amounts of reagent blank and sample blank were added to the tubes, and then $1.5 \mathrm{~mL}$ of FRAP solvent (purified water with $60 \%$ methanol) was added to blank tubes (Benzie and Strain 1996). Finally, $1.5 \mathrm{~mL}$ of freshly prepared FRAP reagent was added to the all tubes except for the sample blank and the tubes were vortexed and kept for 20 minutes. The results were calculated as $\mu \mathrm{M}$ TEAC by compare with the standard antioxidant substance Trolox.

\section{Copper (II) Reducing Antioxidant Activity (CUPRAC)}

In this method, $\mathrm{Cu}$ (II) chloride solution, 96\% neocuproin solution, ammonium acetate buffer $(\mathrm{pH}=7)$ and analysis solutions were added to the reaction tubes, respectively. The final solution volume was completed to $4.1 \mathrm{~mL}$. Tubes were kept at room temperature for 30 minutes. Finally, absorbance values were measured at 450 $\mathrm{nm}$ at the spectrophotometer device (Apak et al., 2004).

As in other tests, the antioxidant capacities of the samples based on Trolox equivalent were calculated as $\mu \mathrm{M}$ TEAC with using graph obtained from the 6 different concentrations of the Trolox antioxidant standard.

\section{ABTS $^{+}$Radical Scavenging Capacity}

In the method, firstly ABTS was dissolved in ethanol: water (5: 1) solvent mixture to prepare a $7 \mathrm{mM}$ ABTS stock solution. The ABTS solution was then mixed with a 2.45 $\mathrm{mM}$ potassium persulfate solution in ethanol: water (1:3). To prepare the ABTS radical cation (ABTS ${ }^{+}$), the mixture was left at room temperature for 18 hours in the dark and then diluted with approximately 1/40 of ethanol: water (3: 2), its absorbance at $734 \mathrm{~nm}$ was adjusted to 0.07 (Re et al., 1999).

The infusion extracts of rosehip tea in different concentrations and the antioxidant standard Trolox solution used in comparison were pipetted in triplicate, as well as for reagent and sample blanks. It was left room temperature for $20 \mathrm{~min}$. At the end of the time, the absorbance values of each were measured at $734 \mathrm{~nm}$. Finally, the amount of the sample in half reducing the ABTS $\bullet^{+}$concentration was calculated as $\mathrm{mg} / \mathrm{mL}$ and the results were expressed as $\mathrm{SC}_{50}$.

\section{Color Change of Infusion Temperatures}

Images of the infusion extracts in glass beaker were transferred to computer for color analysis with Image $\mathbf{J}$ program (Akar and Burnaz, 2019) Determined color values were corelated with infusion temperatures. 

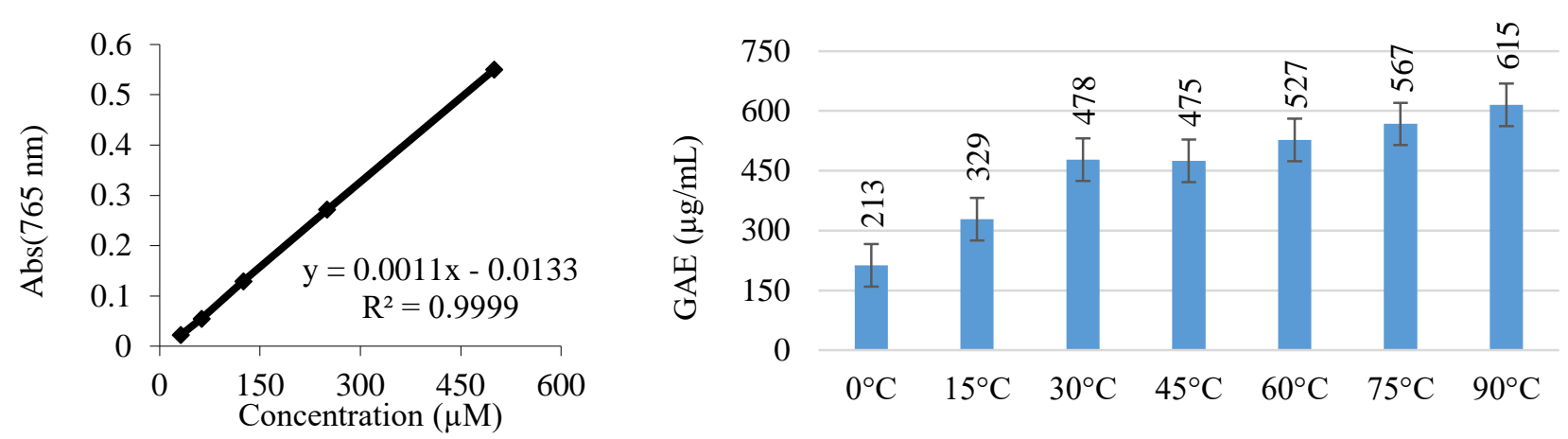

Figure 1. Calibration curve of the gallic acid standard studied at different concentrations (a), values (GAE $\mu \mathrm{g} / \mathrm{mL}$ ) of total phenolic content of rose hip tea bag extracts (b).
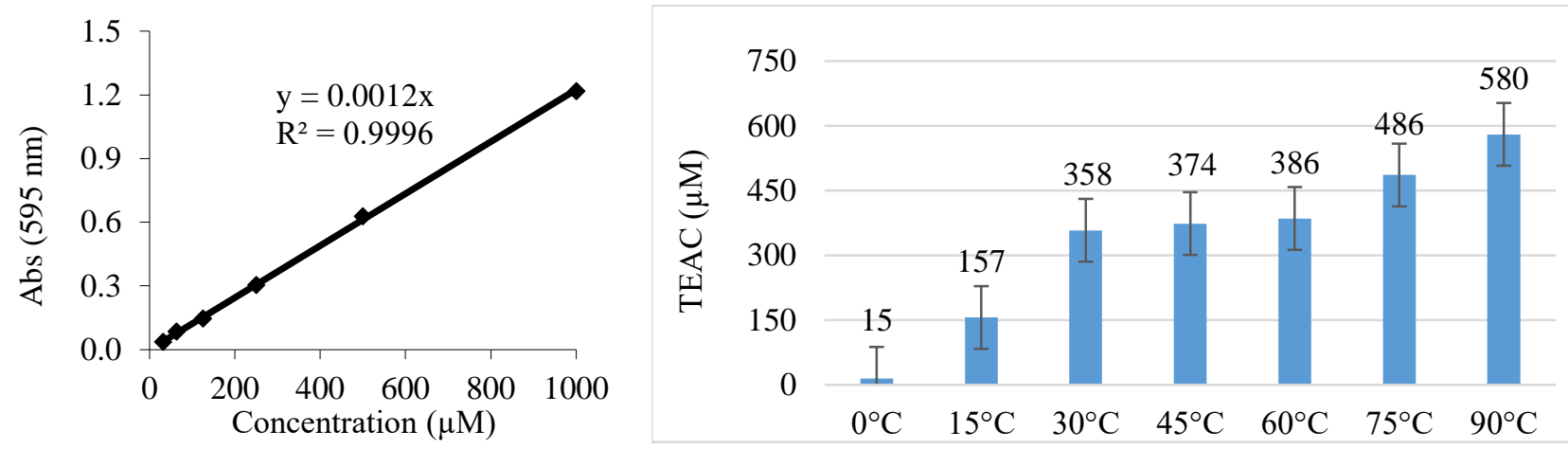

Figure 2. Calibration curve of the Trolox standard studied at different concentrations (a), values (as $\mu \mathrm{M}$ TEAC) of FRAP of rosehip tea bag extracts (b).
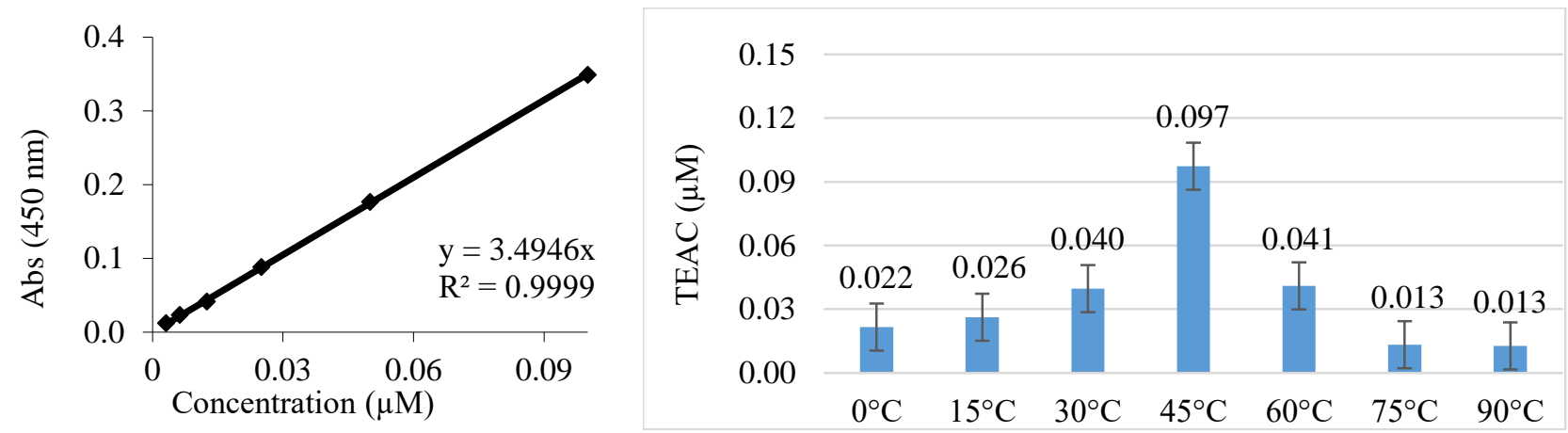

Figure 3. Calibration curve of the Trolox standard studied at different concentrations (a), values (as $\mu \mathrm{M}$ TEAC) of

CUPRAC of rosehip tea bag extracts (b).

\section{Statistical Analysis}

Pearson correlation analyses of the parameters and the graphs were performed using Microsoft Excel version 2019.

\section{Results}

\section{Antioxidant Activity Tests}

\section{Total Phenolic Content}

The total phenolic content of rosehip tea bags infusion at different temperatures calculated as GAE $(\mu \mathrm{g} / \mathrm{mL})$ based on gallic acid antioxidant standard at different concentrations (Figure 1).

As it is seen in the Figure 1 the total phenolic content of the infusions increased together rising temperature, except measured values at $30^{\circ} \mathrm{C}, 45^{\circ} \mathrm{C}$. The difference between the total phenolic contents of both temperatures is negligible. While the highest total phenolic content was measured at $90^{\circ} \mathrm{C}$ with $615 \mathrm{GAE} \mu \mathrm{g} / \mathrm{mL}$, the lowest value was determined at $0^{\circ} \mathrm{C}$ as $215 \mathrm{GAE} \mu \mathrm{g} / \mathrm{mL}$. There is a positive correlation between infusion temperature and TPC values $(\mathrm{r}=0.95 ; \mathrm{P}<0.01)$.

\section{Determination of Iron (III) Reduction / Antioxidant Power (FRAP)}

As in the total phenolic content, the highest and lowest of antioxidant activity values in FRAP was determined at $90^{\circ} \mathrm{C} \quad\left(580 \mu \mathrm{M}\right.$ TEAC) and $0^{\circ} \mathrm{C} \quad(15 \mu \mathrm{M}$ TEAC) respectively and (Figure 2 ). In addition, the values measured in the FRAP method increased with the increasing temperature (Figure 2). There is a positive correlation between both parameters $(r=0.96$; $P<0.01)$.

\section{Copper (II) Reducing Antioxidant Activity} (CUPRAC)

In the CUPRAC test, the calibration graph of the Trolox standard, which was studied at 6 different concentrations, was drawn (Figure 3). Unlike other antioxidant activity 
tests, the highest activity value in the CUPRAC test was measured at $45^{\circ} \mathrm{C}$ as $0.097 \mu \mathrm{M}$ TEAC (Figure 3). However, the lowest activity values were measured at high temperatures $\left(75^{\circ} \mathrm{C}, 90^{\circ} \mathrm{C}\right)$ as $0.013 \mu \mathrm{M}$ TEAC in contrast to other tests. There is no correlation between infusion temperature and CUPRAC values $(r=-0.14)$.

\section{ABTS $^{+}$Radical Scavenging Capacity}

$\mathrm{SC}_{50}$ values for ABTS antioxidant analysis of extracts of rosehip tea bag infusions at 7 different temperatures were measured (Figure 4). The highest activity value was determined at $90^{\circ} \mathrm{C}$ for the with 1.677. As in all the others activity determination methods in the study, the lowest activity value was determined at $0^{\circ} \mathrm{C}$ as 7.931 (Figure 4). There is a negative correlation between infusion temperature and $\mathrm{SC}_{50}$ values $(\mathrm{r}=-0.91 ; \mathrm{P}<0.01)$.

\section{Color Changes of Infusion Temperatures}

The images of rosehip tea bags infusions at the different temperatures were processed by image $\mathrm{j}$ program for color analysis (Akar and Burnaz, 2019). As the infusion temperature increased, the color values increased with the transition of more active ingredients (Figure 5).

\section{$\operatorname{SC50}(\mathrm{mg} / \mathrm{mL})$}

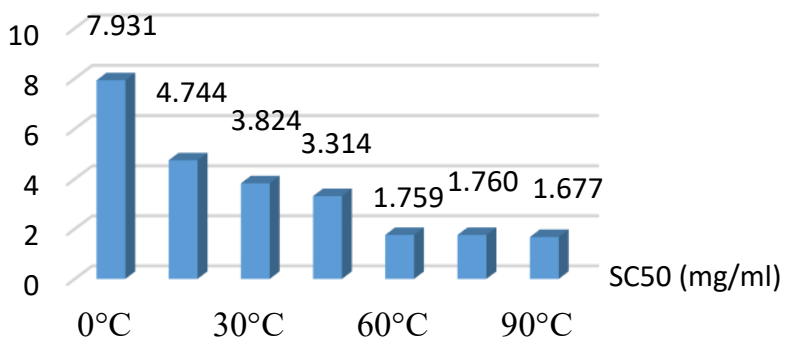

Figure 4. $\mathrm{SC}_{50}$ values of rosehip tea bag extracts (SC50 value of standard Trolox 0.224).
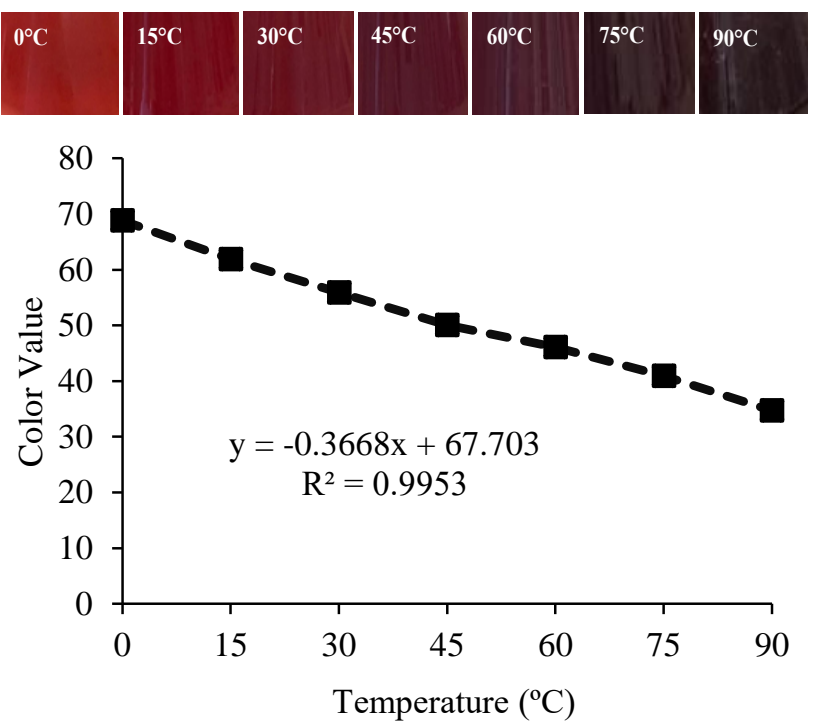

Figure 5. Color changes of rosehip tea bag extracts infusions at different temperatures with Image $\mathbf{J}$ program.

\section{Discussion}

Phenolic compounds found in plants show high antioxidant activity. Many studies have been conducted to determine the antioxidant activity efficiency of phenolic compound composition in plants (Dai and Mumper, 2010). Among these studies, there are investigations that determine the phenolic contents and antioxidant activities of different teas having therapeutic effects at different infusions temperatures (Yıldırım et al., 2015; Saklar et al., 2015; Hajiaghaalipour et al., 2016; Sotiropoulou et al., 2020). Although there is a study to determine the antioxidant properties of cold $\left(28^{\circ} \mathrm{C}\right)$ and hot $\left(100^{\circ} \mathrm{C}\right)$ infusions of white, black and green tea (Camellia sinensis) (Hajiaghaalipour et al., 2016), no study has been conducted to determine cold infusions of rosehip tea. The antioxidant activities of rosehip tea infusions at 7 different temperatures $\left(0-15-30-45-60-75-90^{\circ} \mathrm{C}\right)$ were determined using 4 different activity methods. The highest antioxidant activity values were measured at $90^{\circ} \mathrm{C}$ (the highest temperature) for all the activity methods (TPC, FRAP and ABTS) except the CUPRAC test. At the same time, the lowest values in all the activity methods were determined at the $0^{\circ} \mathrm{C}$.

Temperature is one of the factors that increase the solubility of phenolic compounds. (Spigno et al., 2007; Luthria, 2008; Elboughdiri, 2018). It has been reported in many studies that there is a positive correlation between temperature and antioxidant activity of infusions of both rosehip tea and other teas at different temperature (Yıldırım, 2016; İlyasoğlu and Arpa, 2017; Chang et al., 2020). In these studies, different antioxidant activity determination methods were used; TPC, Total Flavonoid Content and DPPH (Yildırım et al., 2016), TPC and DPPH methods (Chang et al., 2020), TPC and FRAP (Ilyasoğlu and Arpa, 2017). In our study, TPC and FRAP methods were used in common with the other studies. In addition to these methods, CUPRAC and ABTS methods were used for determination antioxidant activity of the rosehip tea. In the CUPRAC method, the highest activity value was determined as $45^{\circ} \mathrm{C}$, and strikingly, even the activity value at $0^{\circ} \mathrm{C}$ was found to be higher than $90^{\circ} \mathrm{C}$, where the highest activity value was determined for other methods. Although there is a positive correlation between increasing temperature and solubility of phenolics, some phenolics denatured at high temperatures (Spigno et al., 2007; Luthria, 2008; Lou et al., 2004). Each of the antioxidant activity tests has different mechanisms and therefore they are sensitive to different phenolic substances (Karadag et al., 2009). The highest activity value at relatively lower temperatures in the CUPRAC test may be an indication that phenolics denatured at high temperatures.

Obtaining the highest activity value at relatively lower temperatures in the CUPRAC test may indicate that infusion of rosehip tea at lower temperatures will provide an advantage in obtaining denatured phenolics at high temperatures.

\section{Conclusion}

The antioxidant activity values of rosehip tea bag infusions at 7 different temperatures (0-15-30-45-60-75$90^{\circ} \mathrm{C}$ ) were determined with antioxidant activity 
determination methods of TPC, CUPRAC, FRAP and ABTS. It was determined that rosehip tea bag had the highest activity values $90^{\circ} \mathrm{C}$ for TPC, FRAP and ABTS methods. However, in the CUPRAC test, the highest value was determined for $45^{\circ} \mathrm{C}$. The data indicate that the rosehip tea infusions at low temperatures may provide an advantage in terms of solubility of some phenolics that may denature at high temperatures. In addition, infusions of rosehip tea at lower temperatures will contribute to reducing the energy costs.

\section{References}

Akar Z, Burnaz NA. 2019. A New Colorimetric Method for CUPRAC Assay with Using of TLC plate. LWT - Food Science and Technology, 112: 108212. doi: https://doi. org/10.1016/j.lwt.2019.05.110

Apak R, Güçlü K, Özyürek M, Karademir SE. 2004. Novel Total Antioxidant Capacity Index for Dietary Polyphenols and Vitamins C and E, Using Their Cupric Ion Reducing Capability in the Presence of Neocuproine: CUPRAC Method. Journal of Agricultural and Food Chemistry, 52: 7970-7981. doi: https://doi.org/10.1021/jf048741x

Benzie IFF, Strain JJ. 1996. The Ferric Reducing Ability of Plasma (FRAP) as a Measure of "Antioxidant Power": the FRAP Assay. Analytical Biochemistry, 239(1): 70-76. doi: https://doi.org/10.1006/abio.1996.0292

Chandrasekara A, Shahidi F. 2018. Herbal Beverages: Bioactive Compounds and Their Role in Disease Risk Reduction-A Review. Journal of Traditional and Complementary Medicine, 8(4): 451-458. doi: https://doi.org/10.1016/ j.jtcme.2017.08.006

Chang MY, Lin YY, Chang YC, Huang WY, Lin WS, Chen CY, Huang SL, Lin YS. 2020. Effects of Infusion and Storage on Antioxidant Activity and Total Phenolic Content of Black Tea. Applied Sciences, 10(8): 2685. doi: https://doi.org/ 10.3390/app10082685

Choi SH. 2009. Essential Oil Components in Herb Teas (rose and rosehip). Journal of Life Science, 19(9): 1333-1336. doi: https://doi.org/10.5352/JLS.2009.19.9.1333

Dai J, Mumper, RJ. 2010. Plant Phenolics: Extraction, Analysis and Their Antioxidant and Anticancer Properties. Molecules, 15(10): 7313-7352. doi: 10.3390/molecules 15107313

Elboughdiri N. 2018. Effect of Time, Solvent-Solid Ratio, Ethanol Concentration and Temperature on Extraction Yield of Phenolic Compounds from Olive Leaves. Engineering, Technology and Applied Science Research, 8(2): 2805-2808. doi: https://doi.org/10.48084/etasr.1983

Gardner EJ, Ruxton CHS, Leeds AR. 2007. Black Tea-Helpful or Harmful? A Review of the Evidence. European Journal of Clinical Nutrition, 61(1): 3-18. doi: https://doi.org/ 10.1038/sj.ejcn.1602489

Garipağaoğlu M, Kuyrukçu N. 2009. Child Health and Caffeine. Journal of Child, 9(3): 110-115.

Hajiaghaalipour F, Sanusi J, Kanthimathi MS. 2016. Temperature and Time of Steeping Affect the Antioxidant Properties of White, Green, and Black Tea Infusions. Journal of Food Science, 81(1): 246-254. doi: https://doi.org/10.1111/17503841.13149

İlyasoğlu H, Arpa TE. 2017. Effect of Brewing Conditions on Antioxidant Properties of Rosehip Tea Beverage: Study by Response Surface Methodology. Journal of Food Science and Technology, 54(11): 3737-3743. doi: https://doi.org/10. 1007/s13197-017-2794-2

Karadag A, Ozcelik B, Saner, S. 2009. Review of methods to determine antioxidant capacities. Food Analytical Methods, 2(1): 41-60. doi: https://doi.org/10.1007/s12161-008-9067-7

Khorshid L, Dilek S. 2013. Caffeine Consumption in Staff in University. Ege Üniversitesi Hemşirelik Fakültesi Dergisi, 29(1): 45-59.
Li S, Lo CY, Pan MH, Lai CS, Ho CT. 2013. Black Tea: Chemical Analysis and Stability. Food and Function, 4(1): 10-18. doi: https://doi.org/10.1039/C2FO30093A

Lou SN, Lin YS, Hsu YS, Chiu EM, Ho CT. 2014. Soluble and Insoluble Phenolic Compounds and Antioxidant Activity of Immature Calamondin Affected by Solvents and Heat Treatment. Food Chemistry, 161: 246-253. doi: https://doi.org/10.1016/j.foodchem.2014.04.009

Łuczaj W, Skrzydlewska E. 2005. Antioxidative Properties of Black Tea. Preventive Medicine, 40(6): 910-918. doi: https://doi.org/10.1016/j.ypmed.2004.10.014

Luthria DL. 2008. Influence of Experimental Conditions on The Extraction of Phenolic Compounds from Parsley (Petroselinum crispum) Flakes Using a Pressurized Liquid Extractor. Food Chemistry, 107(2): 745-752. doi: https:// doi.org/10.1016/j.foodchem.2007.08.074

Meegahakumbura MK, Wambulwa MC, Li MM, Thapa KK, Sun YS, Möller M, Xu JC, Yang JB, Liu J, Li DZ, Gao LM. 2018. Domestication Origin and Breeding History of the Tea Plant (Camellia sinensis) in China and India Based on Nuclear Microsatellites and cpDNA Sequence Data. Frontiers in Plant Science, 8: 2270. doi: https://doi.org/10.3389/fpls.2017. 02270

Petkova N, Ognyanov M, Kirchev M, Stancheva M. 2020. Bioactive Compounds in Water Extracts Prepared from Rosehip-Containing Herbal Blends. Journal of Food Processing and Preservation, e14645. doi: https://doi.org/ 10.1111 /jfpp. 14645

Poswal FS, Russell G, Mackonochie M, MacLennan E, Adukwu EC, Rolfe V. 2019. Herbal Teas and Their Health Benefits: A Scoping Review. Plant Foods for Human Nutrition, 74: 266276. doi: https://doi.org/10.1007/s11130-019-00750-w

Ravikumar C. 2014. Review on Herbal Teas. Journal of Pharmaceutical Sciences and Research, 6(5): 236-238.

Re R, Pellegrini N, Protrggente A, Pannala A, Yang M, RiceEvans C, 1999. Antioxidant Activity Applying an Improved ABTS Radical Cation Decolorization Assay. Free Radical Biology and Medicine, 26: 1231-1237. doi: https://doi.org/ 10.1016/S0891-5849(98)00315-3

Saklar S, Ertas E, Ozdemir IS, Karadeniz B. 2015. Effects of Different Brewing Conditions on Catechin Content and Sensory Acceptance in Turkish Green Tea Infusions. Journal of Food Science and Technology, 52(10): 6639-6646. doi: https://doi.org/10.1007/s13197-015-1746-y

Slinkard K, Singleton VL. 1977. Total Phenol Analysis: Automation and Comparison with Manual Methods. American Journal of Enology and Viticulture, 28: 49-55.

Sotiropoulou NS, Megremi SF, Tarantilis P. 2020. Evaluation of Antioxidant Activity, Toxicity, and Phenolic Profile of Aqueous Extracts of Chamomile (Matricaria chamomilla L.) and Sage (Salvia officinalis L.) Prepared at Different Temperatures. Applied Sciences, 10(7): 2270. doi: https://doi.org/10.3390/app10072270

Spigno G, Tramelli L, De Faveri DM. 2007. Effects of Extraction Time, Temperature and Solvent on Concentration and Antioxidant Activity of Grape Marc Phenolics. Journal of Food Engineering. 81(1): 200-208. doi: https://doi.org/ 10.1016/j.jfoodeng.2006.10.021

Tumbas VT, Čanadanović-Brunet JM, Četojević-Simin DD, Ćetković GS, Đilas SM, Gille L. 2012. Effect of Rosehip (Rosa canina L.) Phytochemicals on Stable Free Radicals and Human Cancer Cells. Journal of the Science of Food and Agriculture, 92(6): 1273-1281. doi: https://doi.org/10.1002/ jsfa.4695

Weisburger JH. 1997. Tea and Health: A Historical Perspective. Cancer Letters, 114(1-2): 315-317. doi: https://doi.org/ 10.1016/S0304-3835(97)04691-0

Yildirim RM, Ozulku G, Toker OS, Baslar M, Durak MZ, Sagdic O. 2017. Modeling of Bioactive Compound Content of Different Tea Bags: Effect of Steeping Temperature and Time. Journal of Food Processing and Preservation, 41(1): e12773. doi: https://doi.org/10.1111/jfpp.12773 